\title{
Téoros
}

Revue de recherche en tourisme

\section{Le Musée des religions de Nicolet}

\section{Michèle Paradis}

Volume 16, numéro 2, été 1997

Tourisme et religion

URI : https://id.erudit.org/iderudit/1074581ar

DOI : https://doi.org/10.7202/1074581ar

Aller au sommaire du numéro

Éditeur(s)

Université du Québec à Montréal

ISSN

0712-8657 (imprimé)

1923-2705 (numérique)

Découvrir la revue

Citer ce document

Paradis, M. (1997). Le Musée des religions de Nicolet. Téoros, 16(2), 45-46. https://doi.org/10.7202/1074581ar d'utilisation que vous pouvez consulter en ligne.

https://apropos.erudit.org/fr/usagers/politique-dutilisation/ 
Michèle Paradis, directrice Musée des religions, Nicolet

C'est en août 1986 que le Musée des religions ouvre ses portes dans des locaux temporaires. Des expositions y sont présentées, des liens se créent avec les représentants de différentes traditions religieuses. Le vif intérêt suscité par les expositions qui y sont présentées, au cours des années qui suivent, incite les dirigeants à poursuivre leurs démarches afin de permettre à ce nouveau musée d'avoir son véritable édifice. Ouvert en 1990 , ce nowveau bâtiment attire le regard par sa pierre de taille grise, sa façade de verre, sa pointe de diamant qui apporte un éclairage particulier au hall. Né du milieu, le Musée des religions connaît depuis un développement important et sa reconnaissance dépasse d'ores et déjà les frontières non seulement du Québec, mais également du Canada.

\section{LA RAISON D'ÊTRE D'UN MUSÉE DES RELIGIONS}

L'Église a toujours exercé une influence profonde qui allait au-delà de ses cbjectifs immédiats d'ordre spirituel. Marquée par un profond traditionalisme, la religion catholique ne connaittra de véritables bouleversements qu'au début des années soixante. Des tendances nouvelles apparaissent et la spiritualité des individus trouve maintenant à s'exprimer dans une plus grande variété d'expériences.

Le Québec connaît également une montée de plus en plus importante de nouveaux groupes et l'existence des communautés multiethniques donne alors au Québec un visage religieux nouveau et différent. Qu'elle soit d'inspiration judéo-chrétienne, orthodoxe, orientale ou autre, toute religion est conditionnée par le temps et l'espace, la place et les circonstances de son histoire. La culture religieuse ne disparaît donc pas, elle se diversifie. Mais comment entrer véritablement en relation avec cette culture sans apprendre les coutumes et les croyances qui lui sont propres ?

\section{LE MUSÉE DES RELIGIONS}

Le Musée des religions existe. Situé au cour du Québec - ni à Montréal, ni à Québec mais au centre - il devient, pour le moins, un atout majeur. Il aborde l'histoire des religions de l'intérieur et non pas uniquement dans un contexte historique, sociologique ou politique. Les religions sont prises comme des faits : elles sont vues, sues comme telles.

Sa mise en place s'est faite au mềme rythme que l'oecuménisme : lentement. À vrai dire, il aura fallu dix ans d'un travail acharné avant de procéder à l'ouverture officielle de son nouvel édifice en 1991, puisque le musée avait ouvert ses portes dans des locaux temporaires en 1986. Bref, ce musée permet d'aller à " l'école $*$ du pluralisme religieux. Il permet d'interroger, de découvrir, de s'attacher aux faits religieux qui caractérisent cha- cune des communautés ethniques présentes sur le territoire québécois. II n'est plus possible de nier la diversité des cultures et des expériences culturelles, spirituelles, et le Musée permet de comprendre les phénomènes religieux, en eux-mêtmes et pour eux-mêmes. Au moyen de formes extérieures (objets de culte, rites, coutumes, etc.), l'invisible devient visible. Le Musée permet d'aller au-delà de la barrière ethnique. Cette institution unique rassemble tout autant qu'elle marque les différences et les ressemblances.

Mais le Musée existe, d'abord et avant tout, parce que la religion a occupé une place de choix dans l'histoire de la sociétế québécoise et que des gens du milieu ont reconnu l'importance indéniable de bâtir ce projet unique d'une institution muséale axée sur les phénomènes religieux, profanes ou sacrés.

Ouvrir un musée c'est une chose ; y présenter des expositions ayant pour thème les religions, c'est autre chose. Depuis l'ouverture du musée en 1986, plus de soixante-cinq expositions y ont été présentées, soit un rythme de dix expositions annuellement. Des facettes des différentes traditions comme le bouddhisme, l'hindouisme, le judaisme, le christianisme et l'islam ont été découvertes. Il va sans dire que des comités conseils sont formés, à chacune des expositions importantes, afin d'assurer la justesse du contenu.

Au cours de l'année 1996, le Musée présentait l'exposition $A U N O M D^{\prime} A L$. LAH ; islam et Musulmanes du Québec. Cette exposition avait pour but de faire 
découvrir le rôle de la religion musulmane dans la vie personnelle, familiale et sociale de musulmanes vivant dans un contexte québécois, mais en relation avec la mémoire de leur passé respectif. Cette exposition a suscité un vif interrêt et a contribué à augmenter considérablement l'achalandage au musće. Un comité conseil, composé de huit femmes musulmanes, avait été formé afin d'élaborer et de valider le contenu.

Au cours de l'été 1997, le musée présente Ora et Labora vie monastique au Québec. Cette exposition veut démontrer que le monachisme (vie des moines et de moniales) appartient aux religions les plus diverses et que des groupes d'individus, voire de marginaux, se soumettent à des règles et des constitutions considérées comme sacrées, de façon à répondre à l'appel de leur Dieu. Des spécialistes de l'Université Laval et de l'Université du Québec à Trois-Rivières ont accepté de collaborer à la réalisation de cette exposition.

Le Musée des religions poursuit donc sa mission première, celle de mettre en valeur un aspect du patrimoine matériel et immatériel. En faisant appel aux techniques modernes disponibles, il diffuse des connaissances utiles, sensibilise davantage ses publics à leur patrimoine religieux et, enfin, tente de promouvoir une compréhension mutuelle et un profond respect entre les cultures. Ce musée est né du besoin et du désir des gens du milieu et le développement exponentiel des moyens de communication ont fait disparaître les frontières, l'isolement. Tout est désormais possible et le Musée des religions, situé à Nicolet, peut dorénavant établir des ponts avec d'autres musées, entre autres, à Taïwan, au Mexique, à New York et en Europe. Depuis son ouverture, le Musée a également travaillé en étroite collaboration avec de nombreux musées au Québec.

Ce qui retient au Musée des religions c'est aussi le rôle de rassembleur qu'il exerce. Il devient un lieu de rencontre des croyances au cour de cette société québécoise devenue pluraliste, mais qui englobe également la différence. Il favorise donc la communication interculturelle.

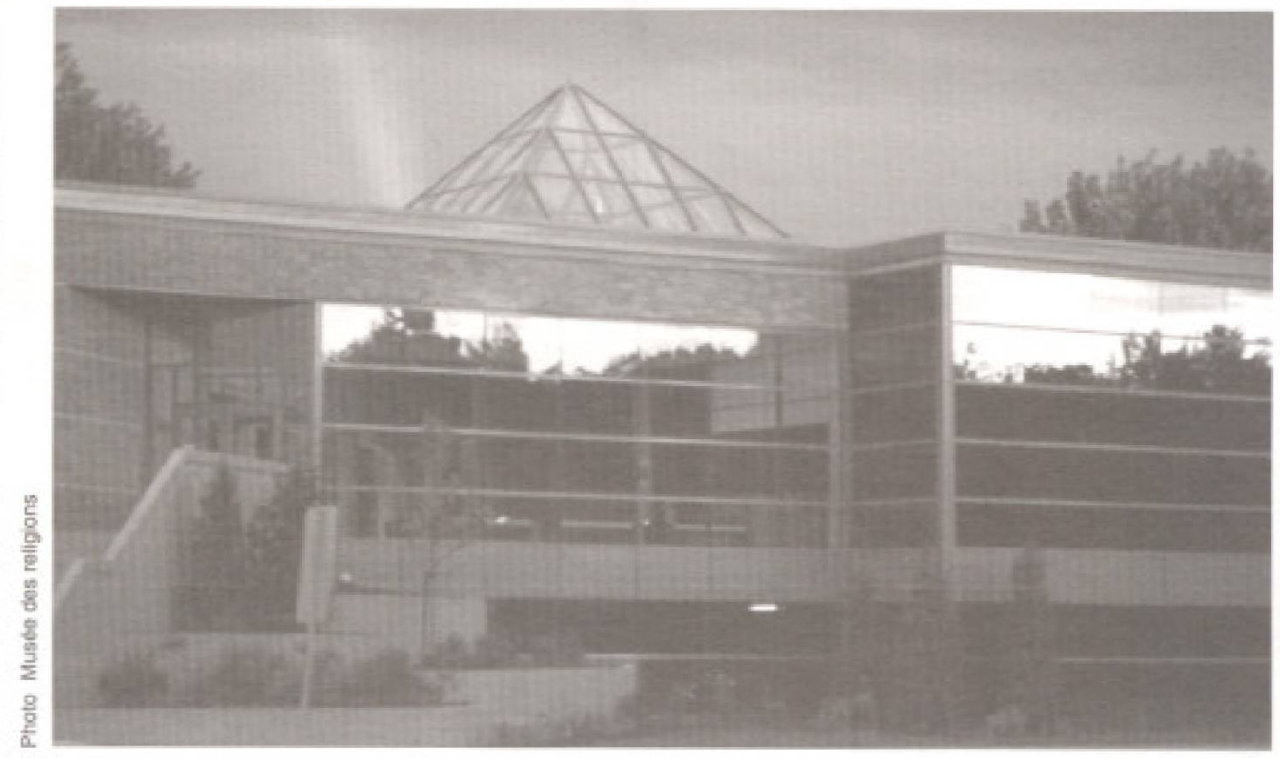

\section{LA SAUVEGARDE DU PATRIMOINE RELIGIEUX}

Le patrimoine religieux est, sans conteste, le patrimoine le plus important de la société québécoise. Grandement menacé, quel avenir lui est réservé ? Au cours des dernières années, nous avons vu naître différents comités de sauvegarde : Mission patrimoine religieux a été mis sur pied afin d'aider les congrégations religieuses et les organismes religieux du Québec à conserver, à faire connaître et à promouvoir leur patrimoine. De plus, la Fondation Patrimoine Religieux a été mise en place par le gouvernement du Québec afin de soutenir les fabriques et les institutions religieuses dans la restauration de leurs églises et de leurs édifices conventuels.

Le Musée des religions a pour mandat d'être un musće au caractène international, situé en région, un musée fortement personnalisé par son caractère public et social, un musée pluraliste en devenir, c'est-à-dire qui vise l'expression religieuse vivante actuelle jusqu'à anticiper le $\mathrm{XXI}^{\leftarrow}$ siècle. Il pourrait devenir, sans aucun doute, un des lieux importants d'aboutissement des objets cultuels qui sont en rupture avec leur fonction initiale. D'ailleurs, le Musée a acquis ou reçu en dépôts, au cours des dernières années, d'importants fonds de communautés qui ont dû fermer leurs portes ou des fabriques qui n'ont pas la possibilité d'entreposer et de conserver adéquatement leurs trésors.

\section{TOURISME ET RELIGIONS}

Le Musée des religions est devenu dans la région une véritable locomotive pour le développement touristique. Il a su, au cours des dernières années, devenir une destination touristique. En effet, les statistiques révèlent que $56 \%$ de ses publics provient de l'extérieur de la grande région Mauricie-Bois-Francs, parce qu'il a su s'intégrer à l'ensemble du produit touristique de la région, à cause de sa thématique unique. Et cette thématique fort * pointue $*$ exige de la direction des ajustements constants en fonction de ses clientèles d'été et d'hiver. Des sondages effectués régulièrement permettent de s'ajuster aux besoins, aux attentes et aux exigences de ces clientèles et de prendre véritablement le virage client.

Élément complémentaire, le Musée devient sans contredit une destination touristique importante. En effet, est-il besoin de préciser qu'on ne peut appuyer l'avenir de l'industrie touristique d'une région sur la présence d'un seul élément ? S'intégrant harmonieusement à l'ensemble d'un produit touristique régional, il contribue ainsi à augmenter l'achalandage, surtout en période estivale.

Grâce à son courrier électronique et à son site Internet, le Musée des religions développe actuellement son réseau de collaboration à travers le monde, contribuant, de cette façon, à l'expansion de l'industrie touristique régionale. 